\title{
MAXIMUM TRANSFORMER RATIO AT WAKEFIELD EXCITATION AT BLOWOUT REGIME IN PLASMA BY ELECTRON BUNCH UNDER SEMI-GAUSSIAN CHARGE DISTRIBUTION
}

\author{
D.S. Bondar ${ }^{1,2}$, V.I. Maslov ${ }^{1,2}$, I.N. Onishchenko ${ }^{1}$ \\ ${ }^{1}$ National Science Center "Kharkov Institute of Physics and Technology”, Kharkiv, Ukraine; \\ ${ }^{2}$ V.N. Karazin Kharkiv National University, Kharkiv, Ukraine \\ E-mail:vmaslov@kipt.kharkov.ua
}

\begin{abstract}
Using $2 \mathrm{~d} 3 \mathrm{v}$ code LCODE, the numerical simulation of nonlinear wakefield excitation in plasma by shaped rela-
\end{abstract} tivistic electron bunch with charge distribution, which increases according to Gaussian charge distribution up to the maximum value, and then decreases sharply to zero, has been performed. Transformer ratio, as the ratio of the maximum accelerating field to the maximum decelerating field inside the bunch, and accelerating the wakefield have been investigated taking into account nonlinearity of the wakefield. The dependence of the transformer ratio and the maximum accelerating field on the length of the bunch was investigated with a constant charge of the bunch. It was taken into account that the length of the nonlinear wakefield increases with increasing length of the bunch. It is shown that the transformer ratio reaches its maximum value for a certain length of the bunch. The maximum value of the transformer ratio reaches six as due to the profiling of the bunch, and due to the nonlinearity of the wakefield.

PACS: 29.17.+w; 41.75.Lx

\section{INTRODUCTION}

The accelerating gradients in conventional linear accelerators are limited to $100 \mathrm{MV} / \mathrm{m}$ [1], partly due to breakdown. Plasma-based accelerators have the ability to sustain accelerating gradients which are several orders of magnitude greater than that obtained in conventional accelerators $[1,2]$. As plasma in experiment is inhomogeneous and nonstationary and properties of wakefield changes at increase of its amplitude it is difficult to excite wakefield resonantly by a long sequence of electron bunches (see $[3,4]$ ), to focus sequence (see [5 - 10]), to prepare sequence from long beam (see [11 13]) and to provide large transformer ratio TR (see [14 - 20]). Providing a large TR is also being studied in dielectric accelerators (see [21 - 26]). In [4] the mechanism has been found and in [27 - 31] investigated of resonant plasma wakefield excitation by a nonresonant sequence of short electron bunches. Due to the rapid development of laser technology and physics [1, 2, 32 39] laser-plasma-based accelerators are of great interest now. Over the past decade, successful experiments on laser wakefield acceleration of charged particles in the plasma in blowout regime have confirmed the relevance of this acceleration [30 - 33, 40]. Evidently, the large accelerating gradients in the plasma accelerators in blowout regime allow to reduce the size and to cut the cost of accelerators. Another important advantage of the plasma accelerators in blowout regime is that they can produce short electron bunches with high energy [32]. The formation of electron bunches with small energy spread was demonstrated at intense laserplasma interactions [41]. Electron self-injection in blowout regime has been studied by numerical simulations (see [37]). Processes of a self-injection of electrons and their acceleration have been experimentally studied in a plasma accelerator [42].

The problem at laser wakefield acceleration is that laser pulse quickly destroyed because of its expansion.
One way to solve this problem is the use of a capillary as a waveguide for laser pulse. The second way to solve this problem is to transfer its energy to the electron bunches which as drivers accelerate witness. A transition from a laser wakefield accelerator to plasma wakefield accelerator can occur in some cases at laserplasma interaction [43].

With newly available compact laser technology [44] one can produce $100 \mathrm{PW}$-class laser pulses with a single-cycle duration on the femtosecond timescale. With a fs intense laser one can produce a coherent X-ray pulse. Prof. T. Tajima suggested [45] utilizing these coherent X-rays to drive the acceleration of particles. Such X-rays are focusable far beyond the diffraction limit of the original laser wavelength and when injected into a crystal it interacts with a metallic-density electron plasma ideally suited for laser wakefield acceleration [45]. In [46 - 50] it has shown that at certain conditions the laser wakefield acceleration is added in blowout regime by a beam-plasma wakefield acceleration.

In [51] point self-injected and accelerated electron bunch was observed in blowout regime.

The wakefield excitation in a plasma and its application for particle acceleration avoids the problem of breakdown in the metal structures of accelerators when fields exceeded the value $100 \mathrm{MV} / \mathrm{m}$ and creates accelerating gradients which are of considerably higher intensity [2, 4, 52 - 54].

The efficiency of electron acceleration by a wakefield excited in a plasma by a sequence of electron bunches is determined by the transformer ratio (TR) $[16-18,21-23,55-70]$. The TR is the ratio of energy acquired by the witness to energy lost by the driver. Approximately, the TR can be defined as $T R=E_{a c} / E_{d e c}$. Where $E_{a c}$ is the maximum accelerating field after the driver bunch (at the end of the first or second bubble). And $E_{\text {dec }}$ is the maximum decelerating field inside driver bunch. 
Earlier in [60] it was shown that in the linear case, using an Gaussian bunch, the TR does not exceed $\mathrm{TR} \leq 2$.

In this work, using a non-linear version of the $2 \mathrm{~d} 3 \mathrm{v}$ code lcode, numerical simulation of excitation of a nonlinear (blowout or bubble mode) wakefield in a plasma by a shaped relativistic electron bunch was performed. Also, the TR was investigated. In a shaped electron bunch, the charge density along it in the longitudinal direction increases approximately in Gaussian (by cosine) from a zero to maximum, and then abruptly breaks off. The dependence of the accelerating field and TR on the length of the bunch $\xi_{\mathrm{b}}$ is studied when the bunch length $\xi_{\mathrm{b}}$ changes from 0 to the length of the nonlinear wake (bubble), $0<\xi_{\mathrm{b}}<\lambda_{\mathrm{NL}} \approx 2 \lambda$. Here $\lambda$ is the linear wavelength. It is taken into account that the length of the nonlinear wakefield increases when the length of the bunch increases. In a strongly nonlinear regime, this problem cannot be solved analytically. Therefore, it was investigated using a nonlinear version of the code lcode with a constant charge of the bunch.

For numerical simulation parameters have been selected: relativistic factor of bunch equals $\gamma_{b}=1000$. The electron plasma frequency is $\omega_{\mathrm{pe}}=\left(4 \pi \mathrm{n}_{\mathrm{r}} \mathrm{e}^{2} / \mathrm{m}_{\mathrm{e}}\right)^{1 / 2}$. We consider the bunch, electrons in which are distributed according to Gaussian in the transverse direction along the radius. $\xi=\mathrm{V}_{\mathrm{b}} \mathrm{t}-\mathrm{z}, \mathrm{V}_{\mathrm{b}}$ is the bunch velocity. Time is normalized on $\omega_{\mathrm{pe}}{ }^{-1}$, distance - on $\mathrm{c} / \omega_{\mathrm{pe}}$, density - on $\mathrm{n}_{\mathrm{r}}$, current $\mathrm{I}_{\mathrm{b}}-$ on $\mathrm{I}_{\mathrm{cr}}=\pi \mathrm{mc}^{3} / 4 \mathrm{e}$, fields - on $\left(4 \pi \mathrm{n}_{\mathrm{r}} \mathrm{c}^{2} \mathrm{~m}_{\mathrm{e}}\right)^{1 / 2}$.

We use the cylindrical coordinate system $(\mathrm{r}, \mathrm{z})$ and draw the plasma and beam densities and longitudinal electric field at some $\mathrm{z}$ as a function of the dimensionless time $\tau=\omega_{\mathrm{p}} \mathrm{t}$.

The longitudinal coordinate $\xi=\mathrm{z}-\mathrm{V}_{\mathrm{b}} \mathrm{t}$ is normalized on $\lambda / 2 \pi$. The values of the $E_{z}, F_{r}$ and $H_{\theta}$ are normalized on $\mathrm{mc}_{\mathrm{pe}} / \mathrm{e}$. Where e, $\mathrm{m}$ are the charge and mass of the electron, $\mathrm{c}$ is the light velocity, $\omega_{\mathrm{pe}}$ is the electron plasma frequency.

We do not take into account the longitudinal dynamics of the bunches, because at the times and energies of the beam according to

$$
\frac{\mathrm{dV}_{\mathrm{z}}(\mathrm{r})}{\mathrm{dr}} \propto \frac{1}{\gamma_{\mathrm{b}}^{3}}, \frac{\mathrm{dV}_{\mathrm{r}}(\mathrm{r})}{\mathrm{dr}} \propto \frac{1}{\gamma_{\mathrm{b}}}
$$

radial relative shifts of beam particles predominate. $V_{z}$, $\mathrm{V}_{\mathrm{r}}$ are the longitudinal and radial velocities of the electron bunches, $\gamma_{b}$ is the relativistic factor of the bunch.

The aim of the paper is the demonstration by the numerical simulation that the TR - an important value in the wakefield method of acceleration of electron bunches, can be increased by a factor of three due to the profiling of the electron-driver-bunch and due to the non-linearity of the excited wakefield.

\section{INVESTIGATION OF THE TRANSFORMER RATIO}

We consider wakefield excitation in the plasma by the bunch near the injection boundary, since the bunch is deformed when the penetration into the plasma is deep. The main purpose of this work - to consider fac- tors which can increase the TR when the bunch excites wakefield in plasma. It is also an important task to search for the optimal length of the bunch to obtain the highest TR.

In Fig. 1 the dependence of the value of the TR on the bunch length is shown for the case of the first bubble.

The value of the TR increases almost linearly with increase of the length of the bunch, until the length of the bunch reaches $1.125 \lambda$. But then after a local maximum at a bunch length of $1.125 \lambda$ the TR increases with bunch length increase. The largest value of the TR is achieved when the bunch length equals $7 \lambda / 4$. I.e. the largest TR is achieved through the interval of the length of the bunch, approximately equal $\lambda / 2$. One can see in Fig. 1 that the TR reaches maximum value $\mathrm{TR}^{1 \mathrm{st}} \approx 5.25$ when the bunch length equals to $7 \lambda / 4$ for the first bubble in the nonlinear regime for profiled bunch. Further increase of a bunch length leads to a decrease of the transformer ratio.

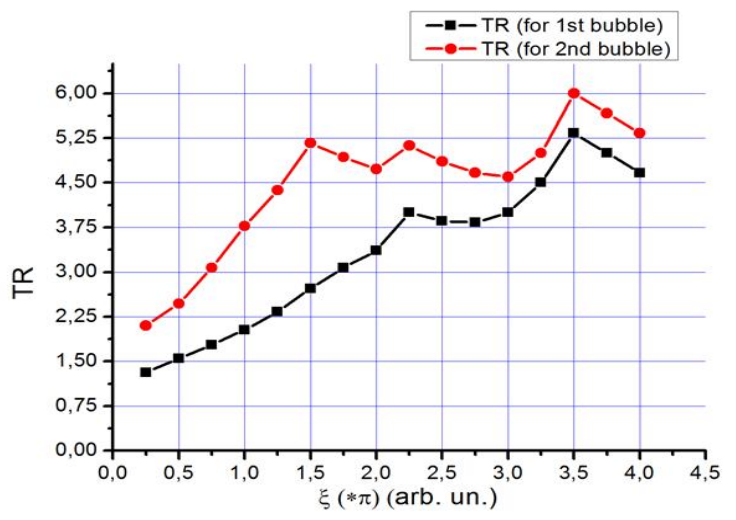

Fig. 1. Dependence of the transformer ratio on the length of the bunch for the 1st and 2nd bubble (normalized by the wavelength of a linear wakefield)

Thus, we can state that the length of the bunch $7 \lambda / 4$ is the optimal length from the point of view of the efficiency of electron acceleration by the excited wakefield, namely by the wakefield at the end of the first wake bubble. $\lambda$ is the wavelength of the linear wakefield.

Further, we consider the TR for the second bubble. One can see in Fig. 1 that in this case the TR behaves in a similar way, as in the case of the first bubble. First, TR increases almost linearly with increasing of the length of the bunch, until the bunch length reaches the value of $3 \lambda / 4$. After that one can see the maximum when the length of the bunch reaches $7 \lambda / 4$ (the interval from the first maximum is $\lambda$ ). When the length of the bunch reaches $1.125 \lambda$, in the both cases of the first and the second bubble, small (relative to the main maximum) jump of the value of the transformer ratio is observed.

Further, after the TR maximal value at length of the bunch $7 \lambda / 4$ the transformer ratio decreases. For the second bubble, the maximum TR for the bunch length $7 \lambda / 4$ is equal to $\mathrm{TR}^{2 \mathrm{nd}} \approx 6.00$. For the subsequent (after the first) bunches, the TR can increase at certain conditions. This can occur due to the accumulation (summation) of the wakefield at approximately the same the decelerating field for all bunches. 
Moreover, it is remarkable that the maximums of the TR are observed at the same length of the bunch after the first and the second bubbles. This leads to the possibility to accelerate two bunches: one bunch at the end of the first bubble, and the second bunch at the end of the second bubble, placing them to the maximum accelerating fields at the bunch length equal to $7 \lambda / 4$.

Further, the dependence of the accelerating field from the length of the bunch in the nonlinear regime was studied for the shaped driver-bunch (Fig. 2). It is observed that the amplitude of the excited nonlinear wakefield decreases (in absolute value) when the length of the bunch increases, similarly to the case of a linear wakefield with an unformed bunch investigated by other authors [55].

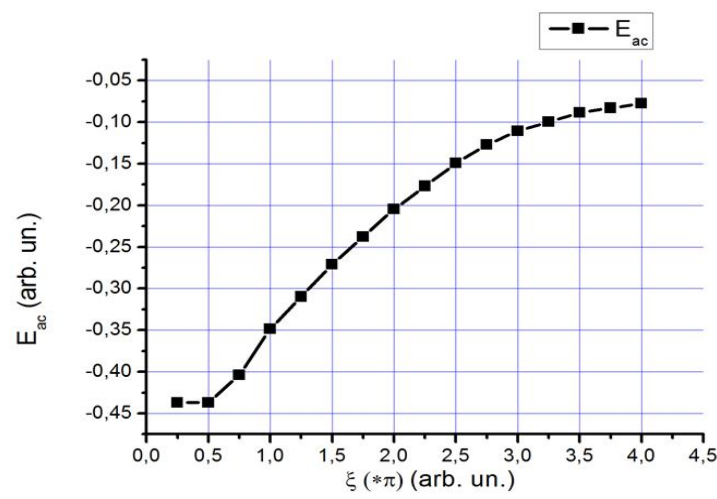

Fig. 2. Dependence of the accelerating field on the length of the bunch for the 1st bubble

This is determined by the finite length of the considered bunch. Indeed, each point of the bunch excites a field whose distribution can be approximately described by a semi-cosine. However, since the fields are excited at different points, some of them are in antiphase and suppress each other. Therefore, the amplitude of the accelerating field decreases with increasing length of the bunch.

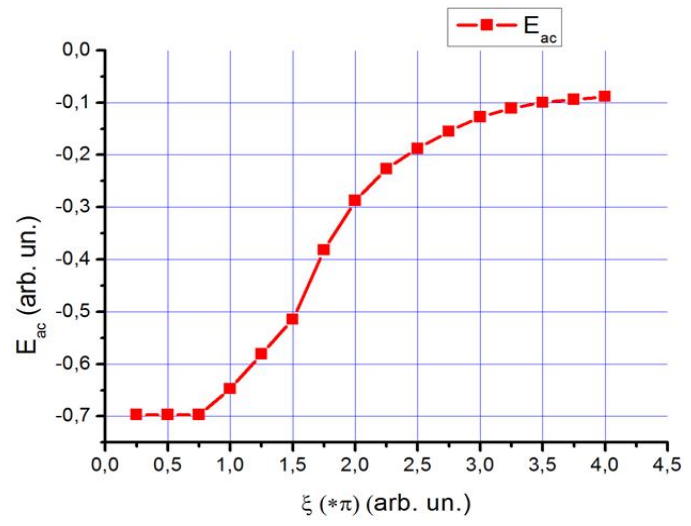

Fig. 3. Dependence of the accelerating field on the length of the bunch for the 2nd bubble

In the case of the second bubble (Fig. 3), a similar dependence is observed: in absolute value, the amplitude of the accelerating field decreases. However, in the case of the second bubble, the amplitude of the accelerating field is initially larger than the amplitude of the accelerating field in the case of the first bubble. Strictly speaking, this leads to an increase of the maximum value of the TR in the case of the second bubble. The excess of the maximum accelerating field after the second bubble over the accelerating field after the first bubble can be explained by the inertness of the plasma electrons, which received a pulse from the driver bunch; and by influence of the space charge of the driver bunch.

In our case, when the length of the bunch increases with a fixed charge of the bunch, i.e. with a fixed number of electrons in the bunch, when electron density in the bunch $n_{b}$ decreases, the bubble lengthens Fig. 4,a,b.

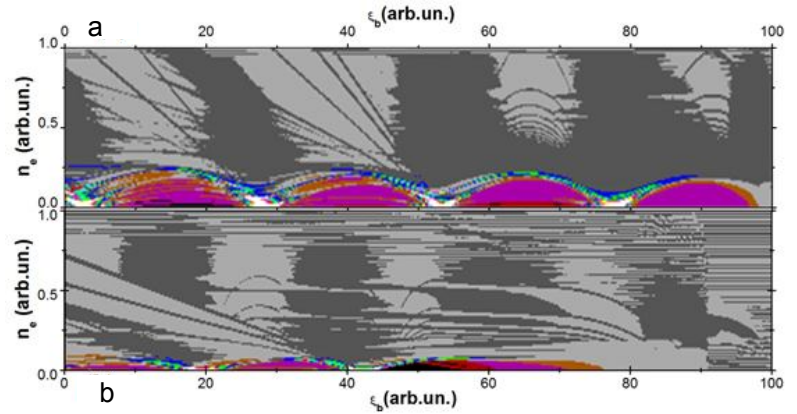

Fig. 4. Spatial distribution of the density of plasma electrons. The figure above (a) is for a bunch length equal to $0.25 \cdot \pi$. The figure below (b) is for the length of the bunch, equal to $3.75 \cdot \pi$

In addition, the dependence of the decelerating field on the length of the bunch was investigated (Fig. 5).

One can see from Fig. 5 that the dependence of the decelerating field on the length of the bunch is a function that decreases monotonically with increasing of the length of the bunch.

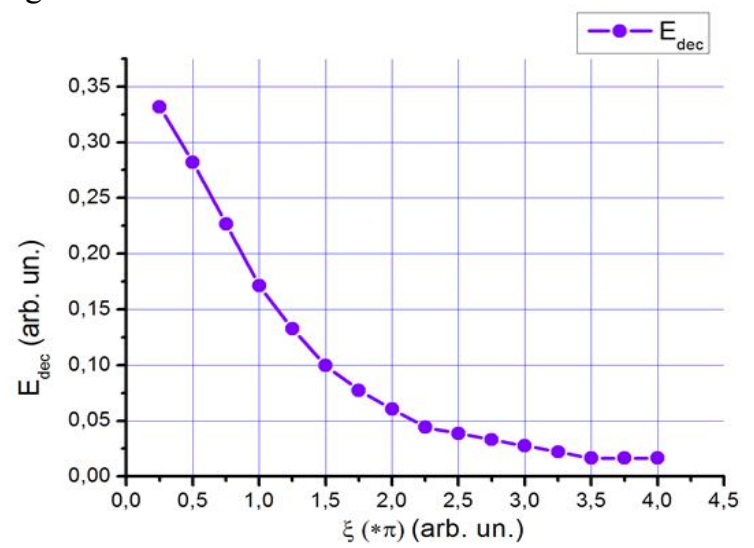

Fig. 5. Dependence of the decelerating field on the length of the bunch

\section{CONCLUSIONS}

Thus, we can state the following. In this paper, it was demonstrated by numerical simulation that the transformer ratio at the wakefield excitation by a bunch of relativistic electrons increases due to the profiling of the bunch, and also due to the nonlinearity of the excited wakefield. The value of the transformer ratio after the second bubble exceeds the transformer ratio after the first bubble. It is shown that for certain values of the length of the bunch, the transformer ratio reaches a maximum value exceeding the transformer ratio in the linear case in the absence of shaping of the bunch. The dependence of the accelerating and decelerating fields 
on the length of the bunch were also investigated and they were established that the obtained dependences agree with the theoretical assumptions.

\section{REFERENCES}

1. E. Esarey, C.B. Schroeder, W.P. Leemans. Physics of laser-driven plasma-based electron accelerators // Rev. Mod. Phys. 2009, v. 81, p. 1229-1285.

2. A. Pukhov, J. Meyer-ter-Vehn. Laser wake field acceleration the highly non-linear broken-wave regime // Apl. Phys. B. 2002, v. 74, p. 355-361.

3. K.V. Lotov, V.I. Maslov, I.N. Onishchenko, et al. Simulation of plasma wakefield excitation by a sequence of electron bunches // Problems of Atomic Science and Technology. 2008, № 6, p. 114-116.

4. K.V. Lotov, V.I. Maslov, I.N. Onishchenko, et al. Resonant excitation of plasma wakefield by a nonresonant train of short electron bunches // Plasma Phys. Cont. Fus. 2010, v. 52, № 6, p. 065009.

5. K.V. Lotov, V.I. Maslov, I.N. Onishchenko, et al. Homogeneous Focusing of Electron Bunch Sequence by Plasma Wakefield // Problems of Atomic Science and Technology. 2012, № 3, p. 159-163.

6. V.I. Maslov, I.N. Onishchenko, I.P. Yarovaya. Plasma Wakefield Excitation, Possessing of Homogeneous Focusing of Electron Bunches // Problems of Atomic Science and Technology. 2013, № 1, p. 134-136.

7. V.I. Maslov, I.N. Onishchenko, I.P. Yarovaya. Fields excited and providing a uniform focusing of short relativistic electron bunches in plasma // East European Journal of Physics. 2014, v. 1, № 2, p. 92-95.

8. I.P. Levchuk, V.I. Maslov, I.N. Onishchenko. Focusing of Relativistic Electron Bunches by Nonresonant Wakefield Excited in Plasma // Problems of Atomic Science and Technology. 2015, № 4, p. 120-123.

9. I.P. Levchuk, V.I. Maslov, I.N. Onishchenko. Focusing by Wakefield and Plasma Focusing of Relativistic Electrons in Dependence on Parameters of Experiments // Problems of Atomic Science and Technology. 2016, № 3, p. 62-65.

10. V.I. Maslov et al. Uniform Focusing of Train of Relativistic Positron Bunches in Plasma // East Eur. J. Phys. 2019, № 2, p. 69-74.

11. K.V. Lotov, V.I. Maslov, I.N. Onishchenko, et al. $2 \mathrm{~d} 3 \mathrm{v}$ Numerical Simulation of Instability of Cylindrical Relativistic Electron Beam in Plasma // Problems of Atomic Science and Technology. 2010, № 4, p. 12-16.

12. K.V. Lotov, V.I. Maslov, I.N. Onishchenko, et al. To the Mechanism of Instability of Cylindrical Relativistic Electron Beam in Plasma // Problems of Atomic Science and Technology. 2011, № 1, p. 8385.

13. V.A. Balakirev, I.N. Onishchenko, V.I. Maslov. Instability of finite radius relativistic electron beam in plasma // Problems of Atomic Science and Technology. 2011, № 3, p. 92-95.
14. K.V. Lotov, V.I. Maslov, I.N. Onishchenko. Transformer Ratio in Wake-Field Method of Acceleration for Sequence of Relativistic Electron Bunches // Problems of Atomic Science and Technology. 2010, № 4, p. 85-89.

15. K.V. Lotov, V.I. Maslov, I.N. Onishchenko, I.P. Yarovaya. Transformer Ratio at Interaction of Long Sequence of Electron Bunches with Plasma // Problems of Atomic Science and Technology. 2011, № 3, p. 87-91.

16. V.I. Maslov, I.N. Onishchenko, I.P. Yarovaya. Transformer Ratio at Excitation of Nonlinear Wakefield in Plasma by Shaped Sequence of Electron Bunches with Linear Growth of Charge // Problems of Atomic Science and Technology. 2012, № 4, p. 128-130.

17. V.I. Maslov, I.N. Onishchenko, I.P. Yarovaya. Wakefield Excitation in Plasma by Sequence of Shaped Electron Bunches // Problems of Atomic Science and Technology. 2012, № 6, p. 161-163.

18. I.P. Levchuk, V.I. Maslov, I.N. Onishchenko. Transformer Ratio at Wakefield Excitation by Linearly Shaped Sequence of Short Relativistic Electron Bunches // Problems of Atomic Science and Technology. 2015, № 6, p. 37-41.

19. I.P. Levchuk, V.I. Maslov, I.N. Onishchenko. Transformer Ratio at Wakefield Excitation in Dissipative Media by Sequence of Electron Bunches // Problems of Atomic Science and Technology. 2017, № 6, p. 43-46.

20. D.S. Bondar, I.P. Levchuk, V.I. Maslov, I.N. Onishchenko. Transformer Ratio Dependence on Bunch Length at Non-Linear Wakefield Excitation in Plasma by Electron Bunch with Gaussian Charge Distribution // East Eur. J. Phys. 2018, v. 5, № 2, p. 72-77.

21. V.I. Maslov, I.N. Onishchenko. Transformer Ratio at Wakefield Excitation in Dielectric Resonator by Shaped Sequence of Electron Bunches with Linear Growth of Current // Problems of Atomic Science and Technology. 2013, № 4, p. 69-72.

22. V.I. Maslov, I.N. Onishchenko. Transformer Ratio at Wakefield Acceleration in Dielectric Resonator // Problems of Atomic Science and Technology. 2014, № 3, p. 99-101.

23. V.I. Maslov, I.N. Onishchenko. Transformer Ratio at Wakefield Excitation in Dielectric Resonator by Sequence of Rectangular Electron Bunches with Linear Growth of Charge // Problems of Atomic Science and Technology. 2014, № 3, p. 95-98.

24. V.I. Maslov, I.N. Onishchenko. To transformer ratio in resonator concept of dielectric wakefield accelerator driven by a tailored sequence of electron bunches // Proc. of the 9th Int. Workshop "Strong Microwaves and Terahertz Waves: Sources and Applications". Nizhny Novgorod, 24-30 July, 2014, 2 p.

25. G.P. Berezina, A.F. Linnik, V.I. Maslov, et al. Transformer Ratio Increase at Wakefield Excitation in the Dielectric Structure by a Shaped Sequence of 
Relativistic Electron Bunches // Problems of Atomic Science and Technology. 2016, № 3, p. 69-73.

26. V.I. Maslov et al. Effect of Transition Radiation and Dispersion Spreading at Achievement of a Large Transformer Ratio of Exciting Bunch Energy into Wakefield in a Dielectric Resonator Accelerator // Problems of Atomic Science and Technology. 2019, № 4, p. 48-54.

27. K.V. Lotov, V.I. Maslov, I.N. Onishchenko, et al. $2.5 \mathrm{D}$ simulation of plasma wakefield excitation by a nonresonant chain of relativistic electron bunches // Problems of Atomic Science and Technology. 2010, № 2, p. 122-124.

28. K.V. Lotov, V.I. Maslov, I.N. Onishchenko, et al. To Plasma Wakefield Excitation by a Nonresonant Sequence of Relativistic Electron Bunches at Plasma Frequency above Bunch Repetition Frequency // Problems of Atomic Science and Technology. 2010, № 6, p. 114-116.

29. K.V. Lotov, V.I. Maslov, I.N. Onishchenko. Long Sequence of Relativistic Electron Bunches as a Driver in Wakefield Method of Charged Particles Acceleration in Plasma // Problems of Atomic Science and Technology. 2010, № 6, p. 103-107.

30. K.V. Lotov, V.I. Maslov, I.N. Onishchenko, I.P. Yarovaya. Mechanisms of Synchronization of Relativistic Electron Bunches at Wakefield Excitation in Plasma // Problems of Atomic Science and Technology. 2013, № 4, p. 73-76.

31. V.I. Maslov et al. Optimal Resonant Asymptotics of Wakefield Excitation in Plasma by Non-resonant Sequence of Relativistic Electron Bunches // Problems of Atomic Science and Technology. 2019, № 1, p. 99.

32. W.P. Leemans et al. Multi-GeV Electron Beams from Capillary-Discharge-Guided Subpetawatt Laser Pulses in the Self-Trapping Regime // Phys. Rev. Lett. 2014, v. 113, p. 245002.

33. A.V. Vasiliev et al. Works in NSC KIPT on Creation and Application of CPA Laser System // Problems of Atomic Science and Technology. 2018, № 4, p. 289.

34. C. Benedetti et al. Numerical investigation of electron self-injection in the nonlinear bubble regime // Phys. Plasmas. 2013, v. 20, p. 103108.

35. A.J. Gonsalves et al. Tunable laser plasma accelerator based on longitudinal density tailoring // Nature Physics. 2011, v. 7, p. 862-866.

36. X. Wang et al. Quasi-monoenergetic laser-plasma acceleration of electrons to $2 \mathrm{GeV} / /$ Nature Communications. 2013, v. 4, p. 1988.

37. T. Tajima, J.M. Dawson. Laser Electron Accelerator // Phys. Rev. Lett. 1979, v. 43, p. 267.

38. X.M. Zhang, T. Tajima, D. Farinella, et al. X-ray Wakefield Acceleration and Betatron Radiation in Nanotubes // Phys. Rev. 2016, AB 19, p. 101004.

39. T. Tajima, K. Nakajima, G. Mourou. Laser Acceleration // Rivista del Nuovo Cimento. 2017, v. 40, p. 33.

40. W.P. Leemans et al. GeV electron beams from a centimetre-scale accelerator // Nature Physics. 2006, v. 2, p. 696.

41. S.P.D. Mangles et al. // Nature. 2004, v. 431, p. 535.

42. O. Lundh, C. Rechatin, J. Lim, et al. Experimental Measurements of Electron-Bunch Trains in a LaserPlasma Accelerator // PRL. 2013, v. 110, p. 065005.

43. S. Corde et al. Mapping X-Ray Emission Region in a Laser-Plasma Accelerator // PRL. 2011, v. 107, p. 215004.

44. G. Mourou et al. Single Cycle Thin Film Compressor Opening the Door to Zeptosecond-Exawatt Physics // EPJ. 2014.

45. T. Tajima. Laser Acceleration in Novel Media // Eur. Phys. J. Spec. Top. 2014, v. 223, p. 10371044.

46. B. Hidding, T. Konigstein, J. Osterholz, et al. // Phys. Rev. Lett. 2010, v. 104, p. 195002.

47. V.I. Maslov, O.M. Svystun, I.N. Onishchenko, et al. Dynamics of Electron Bunches at the Laser-Plasma Interaction in the Bubble Regime // Nuclear Instruments and Methods in Physics Research A. 2016, v. 829 , p. 422-425.

48. V.I. Maslov, O.M. Svystun, I.N. Onishchenko, et al. Joint Wakefield Acceleration by Laser Pulse and by Self-Injected Electron Bunches // Problems of Atomic Science and Technology. 2016, № 6, p. 144147.

49. D.S. Bondar, I.P. Levchuk, V.I. Maslov, et al. Dynamics of Self-Injected Electron Bunches at their Acceleration by Laser Pulse in Plasma // Problems of Atomic Science and Technology. 2017, № 6, p. 76-79.

50. D.S. Bondar, V.I. Maslov, I.P. Levchuk, I.N. Onishchenko. Excitation of Wakefield by a Laser Pulse in a Metal Density Plasma // Problems of Atomic Science and Technology. 2018, № 6, p. 156-159.

51. V.I. Maslov et al. Improvement of Properties of Self-Injected and Accelerated Electron Bunch by Laser Pulse in Plasma, Using Pulse Precursor // East Eur. J. Phys. 2019, № 2, p. 64-68.

52. W.P. Leemans, A.J. Gonsalves, H.-S. Mao, et al. Multi-GeV Electron Beams from CapillaryDischarge-Guided Subpetawatt Laser Pulses in the Self-Trapping Regime // Phys. Rev. Lett. 2014, v. 113, p. 245002.

53. V. Malka. Laser plasma accelerators // Phys. of Plasmas. 2012, v. 19, p. 055501.

54. S.M. Hooker, R. Bartolini, S.P.D. Mangles, A. Tünnermann, L. Corner, J. Limpert, A. Seryi, R. Walczak. Multi-pulse laser wakefield acceleration: a new route to efficient, high-repetition-rate plasma accelerators and high flux radiation sources // Special Issue of J. Phys. B. 2014, v. 47, p 234003.

55. C. Jing, J. Power, A. Zholents. Dielectric Wakefield Accelerator to Drive the Future FEL Light Source // ANL/APS/LS-326. 2011.

56. S.S. Baturin, A. Zholents. Upper limit for the accelerating gradient in the collinear wakefield accelerator as a function of the transformer ratio // Phys. 
Rev. ST Accel. Beams. 2017, v. 20, p. 061302.

57. T. Tajima. Laser acceleration in novel media // Eur. Phys. J. Special Topics. 2014, v. 223, № 6, p. $1037-$ 1044.

58. F. Massimo, A. Marocchino, M. Ferrario, A. Mostacci, P. Musumeci, L. Palumbo. Transformer ratio studies for single bunch plasma wakefield acceleration // Nucl. Inst. and Meth. A. 2014, v. 740, p. 242245.

59. C. Jing, J.G. Power, M. Conde, W. Liu, Z. Yusof, A. Kanareykin, W. Gai. Increasing the transformer ratio at the Argonne wakefield accelerator // Phys. Rev. ST Accel. Beams. 2011, v. 14, p. 021302.

60. P.B. Wilson. Wake Field Accelerators // Invited talk presented at the SLAC Summer Institute on Particle Physics, Stanford, California. 1985, p. 1-45.

61. P. Chen, A. Spitkovsky, T. Katsouleas, W.B. Mori. Transformer ratio and pulse shaping in laser wakefield accelerator // Nuclear Instruments and Methods in Physics Research Section A: Accelerators, Spectrometers, Detectors and Associated Equipment. 1998, v. 410, № 3, p. 488-492.

62. A. Spitkovsky, P. Chen. Longitudinal laser shaping in laser wakefield accelerators // Phys. Lett. A. 2002, v. 296, № 2, p. 125-130.

63. W.P. Leemans, P. Catravas, E. Esarey, C.G.R. Geddes, C. Toth, R. Trines, C.B. Schroeder, B.A. Shadwick, Van J. Tilborg, J. Faure. ElectronYield Enhancement in a Laser-Wakefield Accelerator Driven by Asymmetric Laser Pulses // Phys. Rev. Lett. 2002, v. 89, № 17, p. 174802.

64. B. Jiang, C. Jing, P. Schoessow, J. Power, W. Gai.
Formation of a novel shaped bunch to enhance transformer ratio in collinear wakefield accelerators // Phys. Rev. ST Accel. Beams. 2012, v. 15, p. 011301.

65. F. Lemery, P. Piot. Tailored electron bunches with smooth current profiles for enhanced transformer ratios in beam-driven acceleration // Phys. Rev. ST Accel. Beams. 2015, v. 18, p. 081301.

66. A.M. Altmark, A.D. Kanareykin. Annular Cherenkov high gradient wakefield accelerator: beambreakup analysis and energy transfer efficiency // Journal of Physics: Conference Series. 2012, v. 357, p. 012001.

67. V.A. Balakirev, I.N. Onishchenko, G.V. Sotnikov, Ya.B. Fainberg. Charged particle acceleration in plasma by wakefield of shaped train of relativistic electron bunches // Sov. Plasma Phys. 1996, v. 22, № 2, p. 157-164.

68. K. Nakajima. Plasma Wake-field Accelerator Driven by a Train of Multiple Bunches // Particle Accelerators. 1990, v. 32, p. 209-214.

69. V.I. Maslov, O.M. Svistun. Transformation Ratio at Plasma Wakefield Excitation by Laser Pulse with Ramping of its Intensity according to Cosine // East Eur. J. Phys. 2014, v. 1, № 4, p. 84-87.

70. S.Yu. Kazakov, S.V. Kuzikov, Y. Jiang, L. Hirshfield. High-gradient two-beam accelerator structure // Phys. Rev. ST Accel. Beams. 2010, v. 13, p. 071303.

Article received 05.02.2020

\section{МАКСИМАЛЬНЫЙ КОЭФФИЦИЕНТ ТРАНСФОРМАЦИИ ПРИ ВОЗБУЖДЕНИИ НЕЛИНЕЙНОГО КИЛЬВАТЕРНОГО ПОЛЯ В ПЛАЗМЕ ЭЛЕКТРОННЫМ СГУСТКОМ С ПОЛУГАУССОВСКИМ РАСПРЕДЕЛЕНИЕМ ЗАРЯДА}

\section{Д.С. Бондар, В.И. Маслов, И.Н. Онищенко}

Используя код LCODE, провели 2d3v численное моделирование возбуждения нелинейной кильватерной волны в плазме профилированным релятивистским электронным сгустком с плотностью заряда, нарастающей по закону Гаусса до максимального значения, а потом резко обрывающейся до нуля. Коэффициент трансформации, как отношение максимального ускоряющего поля к максимальному тормозящему полю внутри сгустка, и ускоряющее поле исследованы с учетом нелинейности кильватерной волны. Исследована зависимость коэффициента трансформации и максимального ускоряющего поля от длины сгустка при неизменном заряде сгустка. Учитывалось, что длина нелинейной кильватерной волны увеличивается с увеличением длины сгустка. Показано, что коэффициент трансформации достигает максимального значения при некоторой длине сгустка. Максимальное значение коэффициента трансформации достигает шести как за счет профилирования сгустка, так и за счет нелинейности кильватерной волны.

\section{МАКСИМАЛЬНИЙ КОЕФІЦІЕНТ ТРАНСФОРМАЦІЇ ПРИ ЗБУДЖЕННІ НЕЛІНІЙНОГО КІЛЬВАТЕРНОГО ПОЛЯ В ПЛАЗМІ ЕЛЕКТРОННИМ ЗГУСТКОМ З НАПІВГАУСІВСЬКИМ РОЗПОДІЛОМ ЗАРЯДУ}

\section{Д.С. Бондар, В.І. Маслов, І.М. Оніщенко}

Використовуючи код LCODE, провели 2d3v чисельне моделювання збудження нелінійної кільватерної хвилі в плазмі профільованим релятивістським електронним згустком з щільністю заряду, яка наростає по закону Гауса до максимального значення, а потім різко зменшується до нуля. Коефіцієнт трансформації, як відношення максимального прискорюючого поля до максимального гальмуючого поля всередині згустка, i прискорююче поле досліджені з урахуванням нелінійності кільватерної хвилі. Досліджено залежність коефіцієнта трансформації і максимального прискорюючого поля від довжини згустка при незмінному заряді згустка. Враховувалося, що довжина нелінійної кільватерної хвилі збільшується зі збільшенням довжини згустка. Показано, що коефіцієнт трансформації досягає максимального значення при деякій довжині згустка. 
Максимальне значення коефіцієнта трансформації досягає шести як за рахунок профілювання згустка, так і за рахунок нелінійності кільватерної хвилі. 